\title{
Preludio a la lectura de un corpus sobre Educación y Cultura contemporánea
}

\author{
ROSA ISUSI-FAGOAGA \\ Universitat de València \\ Rosa.Isusi@uv.es \\ ORCID ID:http:/ / orcid.org/0000-0003-3727-3865
}

Comenzamos la presentación de este quinto número de la revista Creativity and Educational Innovation Review [CEIR] de la Universitat de València, parafraseando una obra emblemática de la cultura del s. XX, el Preludio a la siesta de un fauno del compositor francés Claude Debussy. Este poema sinfónico inspirado en el texto de S. Mallarmé, está considerado un hito cultural y determinante en el rumbo de la música del s. XX. Esta obra de concepción interdisciplinar escrita para orquesta en estructura libre empieza con uno de los instrumentos más antiguos y tradicionales como es la flauta. Sin embargo, esta hace sonar una de las melodías más cromáticas e innovadoras de las escuchadas hasta el momento. Con el tema mitológico en el trasfondo de la acción, el fauno se abandona a un ligero sueño donde cobran forma sus deseos y se transforman en un corpus de sonidos que han trascendido a las modas y el paso del tiempo. Y es que Debussy, como él decía, no hacía música impresionista como los críticos se empeñaron en definir, sino que estaba tratando de hacer algo diferente, un efecto de realidad. En este sentido se presenta nuestra revista. En esta realidad actual en la que, además de vivir condicionados por la pandemia global, parece que en nuestro entorno la filosofía y la música pierden presencia en los currículos educativos y la sociedad parece hacer oídos sordos ante ello. En este número de la revista se ofrecen unas voces que reivindican los saberes, conocimientos e ideas enraizados en la esencia de las personas y que siguen de actualidad. Estas a la vez evidencian lo necesario en nuestra sociedad y sistema educativo de la cultura filosófica, sociológica y musical como elementos clave sin los cuales no es posible alcanzar una educación integral de calidad.

En la primera sección Dialogando, Stefano Scarani profesor de composición con medios electroacústicos y audiovisuales en La Escuela Superior de Música Musikene del País Vasco y profesor externo en el máster de Música en la Universitat Politècnica de València, conversa en inglés con Jorge Sastre y Roger Dannenberg, inventores del sistema Soundcool. A lo largo de este diálogo se analiza la trayectoria de este proyecto que utiliza la música, la creatividad y la tecnología digital para educar y el camino recorrido en el que converge el arte con la medicina.

En la sección de texto invitado se ofrece un interesante estudio realizado por Rolf Arnold, catedrático y pedagogo alemán con una dilatada trayectoria en la investigación y gestión de instituciones educativas para personas adultas, que versa sobre la conexión coherente de nuestro pensar, juzgar y actuar y sus consecuencias. La traducción del alemán al español ha estado a cargo de Francesc J. Hernàndez, doctor en filosofía, ciencias de la educación y sociología y profesor titular en la Universitat de València.

Se presentan ocho artículos que tienen en común el estar centrados en el estudio de diversos aspectos de la Educación y Cultura contemporánea. Estos muestran una variedad de perspectivas actuales desde la filosofía, la sociología y la educación musical. 
Comienza esta sección con un texto homenaje dedicado a la filósofa María Zambrano, de la cual se cumple este año el 30 aniversario de su fallecimiento. Las autoras Amparó Zacarés, profesora de la Universitat Jaume I de Castellón y Rosa Mascarell miembro del Patronato de la Fundación María Zambrano, realizan un recorrido por el legado de la considerada filósofa de la Generación del 27. Las autoras hacen hincapié en la variedad y profundidad del pensamiento de esta intelectual, en especial, en el ámbito de la estética y en la revisión que realizó de varios personajes femeninos convirtiéndolos en referentes. Estos referentes siguen de absoluta actualidad y contribuyen a visibilizar la aportación de las mujeres al mundo de la cultura.

A continuación, David Navarro, doctor en filosofía contemporánea por la Universitat de València y profesor en las universidades colombianas Industrial de Santander y Autónoma de Bucaramanga, ofrece un texto a manera de ensayo sobre las consideraciones acerca de la ciencia como cultura. El autor considera la ciencia como un producto histórico y cultural, a la vez que realiza una ponderación racionalista del conocimiento científico y su valor para la sociedad contemporánea.

Seguidamente, se ofrece un trabajo sobre la relación entre la clase social y el acceso a la universidad, a cargo de dos sociólogos de la educación de reconocido prestigio, Alícia Villar y Francesc J. Hernàndez. La autora, además, está comisionada por la rectora de la Universitat de València para el cargo de jefa de Iniciativas de Trayectorias Académicas. El autor, es director del Departamento de Sociología y Antropología Social de la mencionada universidad.

Se ofrece un estudio sociológico sobre otro gran filósofo del s. XX, Ludwig Wittgenstein, del cual se cumple el centenario de la publicación de su Tractatus Logico-philosophicus. El autor, Fernando Rocher Quinteiros, cuenta con una beca de investigación en el departamento de Departamento de Sociología y Antropología Social de la Universitat de València y en su estudio profundiza en las aportaciones de Wittgenstein a los planteamientos de las ciencias sociales focalizando su análisis en el fenómeno religioso.

El texto titulado ¡La memética ha muerto: Larga vida a la memética! de Francesc Sañé DíazSantos de la Universitat Autònoma de Barcelona, ofrece una original perspectiva crítica con raíces filosóficas sobre el actual fenómeno socio-político-digital de los Memes. Con este título que parafrasea el lema o expresión ritual en la sucesión de las monarquías, el autor reflexiona sobre el estatus filosófico de la disciplina llamada memética y se pregunta por la filosofía -como acción del reflexionar filosófico- del mundo mémico y de los Memes, llegando incluso a plantear si no se estará llegando ya a un punto de inflexión, otro antes-y-después en la historia y forma del pensamiento.

Los tres últimos artículos profundizan en la educación musical desde diferentes perspectivas. Las autoras Celia Escudero Carrascal, María Fernández Hawrylak y María Esther Ruiz Palomo, doctoranda y directoras de tesis, respectivamente, en la Universidad de Burgos, exponen una investigación con resultados satisfactorios en la que abordan la educación emocional a través del oído con el objeto de mejorar la atención de alumnado de Educación Primaria con Necesidades Específicas de Apoyo Educativo.

El siguiente artículo versa sobre la enseñanza del trombón jazz en España y está a cargo de Guillem Escorihuela, profesor en Florida Universitaria y en la Universidad Internacional de Valencia y Marcos Bellizzi, profesor en el Conservatorio Superior de Música de Navarra. En este texto los autores hacen balance de los veinte años de trayectoria en los que llevan impartiéndose estas 
enseñanzas en el Grado de Interpretación Musical en los conservatorios españoles, hacen un estudio comparativo en cuanto a contenidos y metodologías docentes y realizan una propuesta de mejora de la calidad de la enseñanza.

La sección de artículos concluye con un estudio sobre las últimas líneas programáticas del proyecto educativo del festival de música contemporánea ENSEMS que se celebra en Valencia. A lo largo de las páginas se muestra la conceptualización y proceso de los diversos proyectos pedagógicos desde una mirada crítica y en relación con la creación musical en la actualidad, que incluyen especial atención a las guías didácticas, los talleres experimentales, las instalaciones sonoras, los conciertos participativos y la hibridación entre el movimiento y la música de nueva creación. Todo ello con el objeto de acercar al público y en especial a la juventud al arte sonoro contemporáneo. Ha sido elaborado por Cristina Cubells, pedagoga musical, directora de escena, doctoranda en el Departamento de Humanidades: Filosofía, Lenguaje y Literatura en la Universidad Carlos III de Madrid y becaria INPhINIT Retaining de la Fundación La Caixa.

En la sección de Reseñas se ofrecen los comentarios de tres libros y dos encuentros científicos. En primer lugar, la reseña de José Beltrán, sociólogo y profesor en la Universitat de València sobre el libro publicado este mismo año titulado María Zambrano, filósofa de la Generación del 27 de las autoras Amparo Zacarés y Rosa Mascarell.

Le siguen las palabras de Alícia Martí, profesora del Departamento de didáctica de la Lengua y Literatura de la Universitat de València, sobre el Vlé Congrés d'Escola Valenciana "Som Ilavors", celebrado en la Facultat de Magisteri este mismo mes de diciembre.

A continuación, el comentario de Vera Massaguer de la Universitat de València sobre el Webinar Internacional con el título Paraules per a l'alliberament. Homenatge 100 aniversari de Paulo Freire, que ha tenido lugar a finales de este año en el que se ha celebrado el centenario del nacimiento de este gran pedagogo brasileño.

Lidia Jaramillo, que cursa el Máster en Profesor/a de Educación Secundaria en la Universitat de València y ha realizado un Máster en Cooperación Internacional por la Universitat Politècnica de València, presenta una reseña sobre el libro de Hartmut Rosa que ha sido publicado con el titulo Resonancia. Una sociología de la relación con el mundo. En este libro el filósofo, sociólogo y politólogo alemán reflexiona sobre la relación humana con el entorno y en especial la capacidad de las personas para resonar o vibrar mediante la empatía, un aspecto necesario para conectar con el mundo que nos rodea.

Concluye esta sección y la revista de este año, Tania Vieites, doctoranda en psicología de la educación en la Universidade da Coruña, que comenta el libro de la autora Laura Peris Reig titulado Outdoor Education. Una forma de aprendizaje significativo sobre la importancia en la actualidad de la naturaleza y los beneficios de la educación fuera de las aulas. 